\title{
POTENCIAL DA TILÁPIA-DO-NILO PARA PROCESSAMENTO EM CONSERVA
}

\author{
JOSÉ RICARDO GONÇALVES* \\ LEONARDO TACHIBANA** \\ MARCIA MAYUMI HARADA HAGUIWARA***
}

\begin{abstract}
A tilápia é um peixe magro de carne branca e com alto teor de proteína. É uma matéria-prima com potencial para o desenvolvimento de produtos de pescado prontos para consumo, tanto para o mercado doméstico como para o mercado internacional. Esse artigo de revisão aborda os principais aspectos do processamento de pescado em conserva, desde a recepção da matéria-prima até o armazenamento do produto final. Destaque foi dado para a evolução da produção nacional de tilápia-do-nilo e sua qualidade para o processamento em conserva, considerando os métodos de insensibilização, problemas com off-flavor e o processamento térmico. Analisando-se os conhecimentos tecnológicos existentes conclui-se que há elementos para o desenvolvimento de pesquisas com resultados promissores.
\end{abstract}

* Doutor em Tecnologia de Alimentos, Pesquisador Cientifico, Instituto de Tecnologia de Alimentos(ITAL), Campinas, SP, Brasil (e-mail:jricardo@ital.sp.gov.br).

** Doutor em Aquicultura, Pesquisador Cientifico, Instituto de Pesca, São Paulo, SP, Brasil (E-mailtachibana@pesca.sp.gov.br.

*** Doutoranda em Ciência e Tecnologia de Alimentos, Pesquisador Cientifico, Instituto de Tecnologia de Alimentos(ITAL), Campinas, SP, Brasil (e-mail:marciamh@ital.sp.gov.br). 


\section{INTRODUÇÃO}

A tilápia é um peixe originário da África e a sua criação para consumo humano já era hábito dos egípcios dois mil anos antes de Cristo. Embora tão antiga, a atividade passou a ser mais difundida somente no século XX (FIGUEIREDO JUNIOR e VALENTE JUNIOR, 2008). Ela é produzida em vários países e, depois da carpa, é a espécie de peixe cultivado mais importante no mundo, com produção de 3,2 milhões de toneladas em em 2012 (FAO, 2014). O grande destaque é a China, que produziu no mesmo ano cerca de $45 \%$ desse total, particularmente nas águas mornas da sua região sul (FITZSIMMONS, ,RAMOTAR e CEROZI, 2013). Segundo o Ministério da Pesca e Aquicultura, no Brasil é a espécie mais cultivada e produzida o ano inteiro, especialmente em regiões de água abundante e temperaturas tropicais, apresentando uma produção superior a 253 mil toneladas em 2011 (BRASIL, 2011b).

No mercado internacional os produtos de tilápia são comercializados na forma resfriada ou congelada. Dentre os grandes consumidores estão os Estados Unidos, que importaram, em 2011 , cerca de 120 mil toneladas de filés congelados no valor de US\$ 522 milhões (em média, US\$ $4.350,00$ por tonelada). $O$ grande fornecedor foi a China com participação de $86 \%$ do produto. Países latino-americanos, como Honduras e Equador, contribuíram com $74 \%$ das importações do produto na forma resfriada no mesmo ano (USDA, 2012).

Para a produção de filés são utilizados os peixes de maior dimensão devido ao rendimento, que depende também do método de filetagem, formato anatômico, habilidade do filetador, densidade de estocagem e espécie (SOUZA e MARANHÃO, 2001). Os menores peixes são direcionados para mercados menos exigentes ou para a fabricação de subprodutos.

Uma alternativa para aproveitar as tilápias de menor valor comercial está no desenvolvimento de produtos com maior valor agregado, priorizando-os para a alimentação humana. Segundo projeções para 2020, a população brasileira será de 207 milhões de habitantes e o consumo de pescado atingirá a marca de $15,3 \mathrm{~kg}$ per capta/ano. Tal evolução ocorrerá mediante a racionalização da pesca extrativista e o crescimento da aquicultura (BRASIL, 2011a). Isso já acontece em relação à sardinha capturada no Brasil, cuja demanda tem sido atendida com a importação de 30 mil toneladas/ ano, provenientes de países africanos ou europeus, resultando na saída de US\$27 milhões/ano em divisas do País, em valores médios (BRASIL, 2012). Então, a tilápia pode representar matéria-prima suplementar para a indústria de pesca, particularmente nos períodos de defeso da sardinha, quando há elevação de preço do produto em função da redução da oferta e do aumento da ociosidade das instalações industriais. A criação de peixes possui grande vantagem em relação à pesca extrativista, pois permite melhor controle da qualidade do pescado, reduz a sazonalidade da oferta de pescados e a pressão sobre os estoques pesqueiros naturais dos oceanos e rios.

Dentre os processos tradicionais de industrialização, a fabricação de conservas oferece segurança microbiológica e vida útil superior a 1 ano em temperatura ambiente, portanto, dispensando o uso da refrigeração. Embora a população ainda associe esse termo a produto que contém conservantes químicos, o único agente de conservação é o tratamento térmico (esterilização), capaz de destruir esporos de Clostridium botulinum e outras formas de menor resistência térmica, sejam patogênicas ou não, com capacidade de crescimento em temperatura ambiente (GONÇALVES e GERMER, 1992).

Como a intensidade do tratamento térmico é drástica, faz-se necessário dimensionar o processo de esterilização de modo a minimizar possíveis alterações nas características sensoriais originais do produto, especialmente quanto ao sabor, textura e suculência. Nesse aspecto, a embalagem flexível autoclavável (pouch) permite a redução do tempo de esterilização em comparação com as latas convencionais em razão do seu perfil plano e da alta relação área/volume (PAGE, 2010). Ademais, ela já faz parte da rotina na indústria de conservas de pescado e tem boa aceitação pelo consumidor.

Como poucos trabalhos especificos sobre tilápia em conserva foram encontrados efetuou- 
se revisão de literatura para analisar o seu potencial como matéria-prima para a industrialização desse tipo de produto, abordando a evolução da sua produção no Brasil e os principais aspectos de qualidade durante as etapas do processamento.

\section{ORIGEM E HISTÓRICO DA ESPÉCIE NO BRASIL}

Segundo Kubitza (2005), são reconhecidas mais de 70 espécies de tilápia no mundo, mas apenas quatro contribuem de maneira significativa para a composição do pool genético utilizado nos cultivos comerciais: a tilápia-do-nilo (Oreochromis niloticus), a tilápia-azul (Oreochromis aureus), a tilápia-de-moçambique (Oreochromis mossambicus) e a tilápia-de-zanzibar (Oreochromis uroleps hornorum).

A Tilapia rendalli, também conhecida como tilápia-do-congo em razão da sua origem, foi introduzida no Brasil em 1953 (CASTAGNOLLI, 1992). No entanto, devido ao seu baixo desempenho em crescimento, foi superada pela tilápia-do-nilo, que se tornou a espécie mais criada no Brasil. A tilápia-do-nilo apresenta excelente crescimento, boa qualidade da carne, ausência de espinhas em "Y" e boa aceitação por parte do consumidor brasileiro (FIGUEIREDO JUNIOR e VALENTE JUNIOR, 2008).

A partir de 1971 foram realizadas algumas ações para a disseminação da tilápia-do-nilo com a implementação de programa oficial de produção de alevinos em reservatórios públicos no nordeste. Nos Estados de São Paulo e Minas Gerais, as companhias hidrelétricas também contribuíram para essa finalidade. Porém, as tentativas não alcançaram os resultados esperados pela falta de conhecimento e difusão de técnicas de manejo criatório (FIGUEIREDO JUNIOR e VALENTE JUNIOR, 2008).

Somente após 1990 os produtores adotaram a tecnologia de reversão sexual da tilápia e a atividade se tornou importante nas regiões sul e sudeste do Brasil, com destaque para o oeste paranaense. Em 1996, a introdução da tilápia-do-nilo variedade tailandesa (ou chitralada) melhorou o desempenho de crescimento. O sistema de criação em tanques-rede de pequeno volume e alta densidade possibilitou a expansão da tilapicultura nos reservatórios de São Paulo, Minas Gerais e do Paraná. Pouco depois, a tecnologia chegou ao reservatório da Usina Hidrelétrica de Xingó, no Rio São Francisco, e foi difundida por todo o nordeste brasileiro. Paralelamente, a indústria de ração iniciou o desenvolvimento de produtos para o atendimento das necessidades nutricionais do peixe criado em sistemas intensivos (KUBITZA, 2011).

Enquanto os pequenos estabelecimentos paranaenses comercializavam filés congelados e outros produtos, surgiram os chamados pesque-pague: locais em que o cliente pesca em viveiros e pode solicitar a preparação do peixe para consumo em restaurantes instalados no mesmo ambiente (FIGUEIREDO JUNIOR e VALENTE JUNIOR, 2008). A popularização desta atividade elevou os preços da tilápia viva e inviabilizou o funcionamento de muitos frigoríficos. Com a estabilização da demanda pelos pesque-pague no início dos anos 2000, houve a retomada dos projetos de produção e processamento de tilápia nas regiões sul e sudeste do Brasil (KUBITZA, 2011).

Em 2004, o Ceará assumiu a liderança da produção de tilápia e impulsionou seu consumo no Estado a partir da sua oferta como peixe fresco inteiro ou eviscerado, ou ainda, comercializado vivo (KUBITZA, 2011). Os produtores organizaram melhor a cadeia produtiva fazendo as adequações tecnológicas e propondo políticas públicas compatíveis com a nova realidade do setor (FIGUEIREDO JUNIOR e VALENTE JUNIOR, 2008).

Novos frigoríficos foram construídos, principalmente nas regiões sul e sudeste, com o intuito de exportação de filés para os Estados Unidos. Mas, com a desvalorização do dólar diante da moeda nacional no início de 2005 , os frigoríficos direcionaram as produções de filés com padrão exportação para o mercado interno. $O$ evento surpreendeu o consumidor pela qualidade do produto e impulsionou o mercado doméstico (KUBITZA, 2011). 


\section{ESTATÍSTICA DA PRODUÇÃO NACIONAL}

O Brasil vem produzindo alguns tipos de pescado e suas espécies variam conforme a região geográfica. Até o ano de 2007 os números oficiais podem ser encontrados por espécie produzida em cada região, estado e o total nacional, formato que contribui para análise mais detalhada da atividade. A partir daí foram publicados apenas o total anual produzido de cada espécie no Brasil (BRASIL, 2011b).

De modo geral, a tilápia tem presença marcante no nordeste, sudeste e sul do Brasil. O Ceará, um dos grandes destaques nacionais, instituiu em 2011 a Câmara da Cadeia Produtiva de Tilápia para acompanhar o desenvolvimento do setor. A seu favor contam as condições climáticas, utilização de açudes, bom nível de consumo, dentre outros fatores. No sul, o Paraná foi o primeiro a organizar estrutura profissional para a comercialização de tilápia e forma com Santa Catarina importante centro dessa atividade. No entanto, o inverno rigoroso da região provoca a sazonalidade da produção. No sudeste, São Paulo tornou-se o principal produtor, notadamente na sua região noroeste devido ao clima mais favorável ao crescimento da tilápia e disponibilidade de grandes reservatórios de água de hidroelétricas.

A evolução da produção nacional da tilápia nos anos de 1994 a 2011 está demonstrada na Figura 1. No início do período, os números revelam produção de 11,5 mil toneladas/ano. Com o desenvolvimento tecnológico ocorrido na década de 1990 houve intenso crescimento da produção do pescado. Entre 1996 e 2005, calcula-se crescimento médio anual de 22,9\%. Segundo Figueiredo Junior e Valente Junior (2008), as 67,8 mil toneladas produzidas em 2005 superaram, no mesmo ano, a produção conjunta de Equador, Honduras, Costa Rica e Colômbia, tradicionais países exportadores de filé fresco de tilápia para os Estados Unidos. Os autores também mencionam que quase toda produção nacional foi comercializada no mercado interno sem grande esforço de divulgação. Nos anos seguintes, estimulado pelo aumento de consumo, a produção continuou crescendo em ritmo similar, totalizando mais de 253 mil toneladas em 2011.

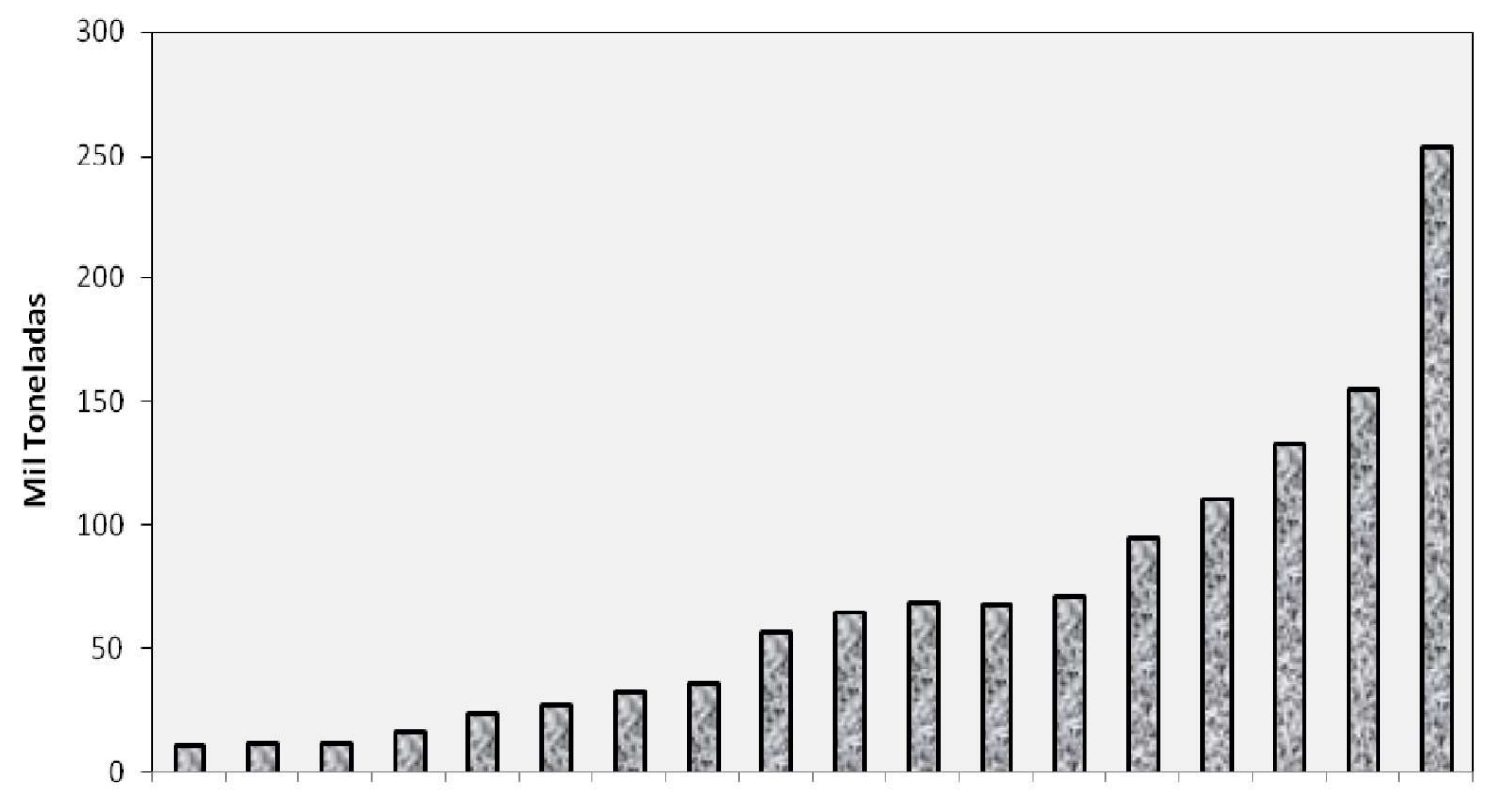

199419951996199719981999200020012002200320042005200620072008200920102011

Ano

\section{FIGURA 1 - EVOLUÇÃO DA PRODUÇÃO BRASILEIRA DE TILÁPIA}

Fonte: Ministério da Pesca e Aquicultura, 2011b. 
O crescimento da produção de tilápia coincide com a expansão da indústria de ração para peixes. Esse segmento duplicou a sua produção no período de 2007 a 2010, estimando-se crescimento médio anual de $27 \%$. Atribui-se boa parte dessa expansão ao ingresso de piscicultores na atividade e à intensificação dos sistemas produtivos, principalmente com a utilização de tanquesrede (FIRETTI et al., 2011).

Existe a expectativa de aumentar a produção de tilápia utilizando-se o reservatório da Usina Hidrelétrica de Itaipu. Conforme a assessoria de imprensa da Itaipu Binacional, a iniciativa representa antiga reivindicação de produtores do oeste do Paraná e poderá dobrar a produção de pescado brasileiro. A concretização dessa expectativa ainda depende de acordo entre Brasil e Paraguai (que restringe o cultivo de espécies exóticas) e de estudos de viabilidade econômica (BRASIL, 2013).

\section{MANEJO DA QUALIDADE}

\subsection{DEPURAÇÃO E OFF-FLAVOR}

O cultivo de tilápia em água salgada ou salobra, particularmente das linhagens vermelhas, resulta em carne com sabor que se assemelha ao de peixes marinhos e pode proporcionar produtos com qualidade diferenciada (KUBITZA, 2005). No cultivo em água doce é comum a formação de sabor e odor estranhos, cujos componentes permeiam mais facilmente através das brânquias, causando dificuldades para a aceitação do produto no mercado e prejuízos ao produtor (BIATO, 2005). Segundo Venugopal (2006), o fenômeno é comum em peixes de água doce ou de águas de baixa salinidade (inferior a 3 partes de sal por mil partes de água).

Souza, Mathies e Fioravanzo (2012) apresentaram revisão sobre as possíveis causas e soluções para a minimização dos níveis de off-flavor na aquicultura, destacando a geosmina (GEO) e o 2-metilisoborneol (MIB) como responsáveis, respectivamente, pelo odor de terra e odor de bolor na água. Esses compostos orgânicos altamente odoríferos são produzidos, principalmente, pela proliferação de cianobactérias em ambientes aquáticos que sofrem processo de eutrofização, caracterizado por desequilíbrio ambiental e níveis elevados de nutrientes, sendo favorecido pela contaminação por esgoto urbano, fertilizantes, agrotóxicos e outros fatores. Há espécies produtoras de toxinas altamente hepatotóxicas, mas, aparentemente, a dose letal para humanos é muito maior que para peixes, o que talvez explique a ausência de intoxicação de pessoas atribuídas a esses dois compostos. O off-flavor pode ser percebido por julgadores profissionais, utilizando uma metodologia descrita na ISO 13301. Os valores mínimos detectáveis por avaliação sensorial para GEO e MIB são 8,4 e 0,8 ppb, respectivamente (VENUGOPAL, 2006). A detecção de off-flavor também pode ser realizada por consumidores treinados, os quais adquirem maior nível de percepção que os consumidores comuns. Uma amostra lavada, cozida em forno de micro-ondas é avaliada quanto ao sabor e odor antes do agendamento da despesca. Em caso de aprovação realiza-se nova avaliação um dia antes da despesca e se houver reprovação essa é cancelada. Por fim, avalia-se uma amostra diretamente do veículo de transporte e se algo for detectado o pescado é devolvido ao produtor (a compra não se concretiza). Em produções bem controladas, o uso desse método pode dispensar a necessidade de depuração, caso os peixes prontos para despesca apresentem níveis aceitáveis de sabor e odor. Há, ainda, técnicas instrumentais amplamente empregadas como o uso de cromatografia gasosa e espectrometria de massa. Embora o controle da eutrofização exija recursos tecnológicos e econômicos, a necessidade de depuração poderá comprometer o processo de produção e fornecimento para o mercado, gerando atrasos, custos adicionais e ocupação de espaço por mais tempo na propriedade rural. Tais autores sugerem reflexão sobre as boas práticas de manejo, diminuição da densidade de estocagem e o uso consciente de antiparasitários.

Uma vez expostos a águas contendo MIB e GEO os peixes adquirem off-flavor em poucas 
horas, mas a reversão do processo pode levar vários dias ou semanas (KUBTIZA, 2000). Souza, Mathies e Fioravanzo (2012) relataram que a velocidade de eliminação desses odores depende das espécies, sendo mais favorável para peixes magros e águas mornas, condição na qual os níveis aceitáveis de MIB e GEO são atingidos em menos de 60 horas. Ainda que o pescado seja magro, como no caso da tilápia, temperaturas mais baixas reduzem o seu metabolismo e podem prolongar o período de depuração por uma semana ou mais. Consequentemente aumentam as chances de infecções por fungos e bactérias antes que a depuração seja concluída, trazendo prejuízos econômicos para sua comercialização (KUBTIZA, 2000).

Biato (2005), estudando a detecção e controle do off-flavor em tilápia-do-nilo conseguiu bons resultados realizando a depuração em até sete dias em tanque com água corrente e limpa, isenta de GEO e algas. Nesse período, os peixes atendiam os limites microbiológicos estabelecidos pela legislação. Contudo, o período ideal para a eliminação do off-flavor foi de 5 dias, havendo perda de peso de $8,5 \%$ em relação ao peixe não depurado. $O$ autor também afirmou que o processo de defumação é capaz de atenuar a percepção desse problema no pescado não depurado.

Quanto ao aspecto operacional, o cultivo e a depuração podem ocorrer no mesmo tanque ou em tanques independentes, (nesse caso, ocupando maior espaço e volume de água). A existência do tanque de depuração é mais comum em frigoríficos de pequeno porte, devido ao menor volume de peixes (e consequentemente de água) para receber o referido tratamento (KUBTIZA, 2000).

\subsection{INSENSIBILIZAÇÃO, ABATE E QUALIDADE DO PESCADO REFRIGERADO}

A captura e o método de insensibilização do pescado devem ser realizados de modo a reduzir ao máximo o seu nível de estresse, o qual está associado à qualidade da carne. Os métodos mais comuns de insensibilização para abate são a imersão em gelo ou em água gelada durante $10 \mathrm{a}$ 15 minutos, caracterizando a termonarcose ou choque térmico (PEDRAZZANI et al., 2009). Porém, outros métodos têm sido estudados.

Pedrazzani et al.(2009) avaliaram a insensibilização de tilápia-do-nilo por dois métodos: secção da medula e termonarcose. O tempo para atingir a inconsciência dos peixes foi menor no primeiro método, 82 versus 750 segundos, respectivamente $(p<0,01)$. Não houve diferença entre os tratamentos em relação ao $\mathrm{pH}$ e rigor mortis $(p>0,05)$, mas foi demonstrado que a secção da medula representa método de insensibilização superior quanto ao bem-estar animal. Os autores mencionaram que o tipo de faca utilizado interfere no desempenho do método e sugerem o aperfeiçoamento da técnica para promover a inconsciência imediata dos peixes.

Albuquerque, Zapata e Almeida (2004) compararam a insensibilização da tilápia-donilo por 10 minutos em água saturada com $\mathrm{CO}_{2}$ e em mistura de água e gelo (esse ocupando $1 / 4$ do volume de água). Após esse período, os peixes sofreram o corte dos arcos branquiais e sangramento durante 5 minutos em água limpa. Nos dois tratamentos foram observados sinais de atordoamento, mas durante o sangramento em água à temperatura ambiente a recuperação da atividade foi mais rápida nos peixes atordoados em água e gelo. Nestas condições, foi verificado que a insensibilização conduzida com $\mathrm{CO}_{2}$ permite o sangramento e a morte da tilápia-do-nilo de forma menos estressante, embora o outro método possa ser mais simples e econômico. Durante o armazenamento em gelo por 7 dias, o tratamento com $\mathrm{CO}_{2}$ manteve a boa condição do cristalino do olho e da cor das brânquias, que são indicadores importantes na comercialização do pescado junto ao consumidor. No período de 17 dias de armazenamento em gelo, os autores não encontraram efeito significativo $(p>0,05)$ entre os métodos sobre as características físicas e de composição centesimal da parte muscular do pescado.

Rodrigues et al.(2008) avaliaram a qualidade da tilápia-do-nilo insensibilizada por choque térmico, abatida, eviscerada e armazenada em gelo (2 peixe: 1 gelo) e mantida em refrigerador doméstico a $0,3{ }^{\circ} \mathrm{C}$ por 28 dias. As contagens de mesófilos e psicrotróficos permaneceram de acordo com limites aceitáveis até 18 dias. 0 Teste de Aceitação revelou altos valores de aceitação 
para o pescado por até 15 dias, mas a partir desse período houve aumento na intensidade de percepção dos atributos não desejáveis observados pela Análise Descritiva Quantitativa. Com base nos resultados deste experimento foi sugerido o prazo de validade comercial de 15 a 18 dias para tilápia eviscerada e armazenada em gelo.

Soccol (2002) conduziu experimentos com tilápia-do-nilo insensibilizada por choque térmico, abatida, eviscerada e filetada para estudo da vida útil. Parte dos filés foi imersa durante 2 minutos em solução de ácido acético a 1\% (1,2 filé: 1ácido), enquanto outra recebeu a imersão em água destilada nas mesmas condições, formando a amostra controle. Posteriormente, todas as amostras foram embaladas em bandejas envolvidas em filme plástico sob três condições (atmosfera normal, vácuo e atmosfera modificada) e armazenadas a $1^{\circ} \mathrm{C}$ por até 20 dias. Quanto aos aspectos físico-químicos e microbiológicos todos os tratamentos foram satisfatórios durante o período estudado, mas as amostras não tratadas (controle) apresentaram contagem de psicrotróficos e pH acima do considerado aceitável aos 13 dias de armazenamento, sinalizando seu limite de vida útil.

\subsection{PROCESSAMENTO DE CONSERVAS DE PESCADO}

Salvo regulamentos específicos, as conservas são produtos obtidos a partir de pescado íntegro, fresco ou congelado, descabeçado e eviscerado, envasado em recipientes hermeticamente fechados e submetidos a tratamento que assegure a esterilidade comercial, permitindo o seu armazenamento e distribuição em condições normais (BRASIL, 2011a). Deve-se salientar a importância da baixa contagem microbiológica das matérias-primas e ingredientes, integridade da embalagem, esterilização dimensionada, resfriamento rápido e manuseio adequado dos produtos pós-processamento. A Figura 2 apresenta fluxograma básico de processamento de pescado em conservas, seguida da descrição das principais etapas.

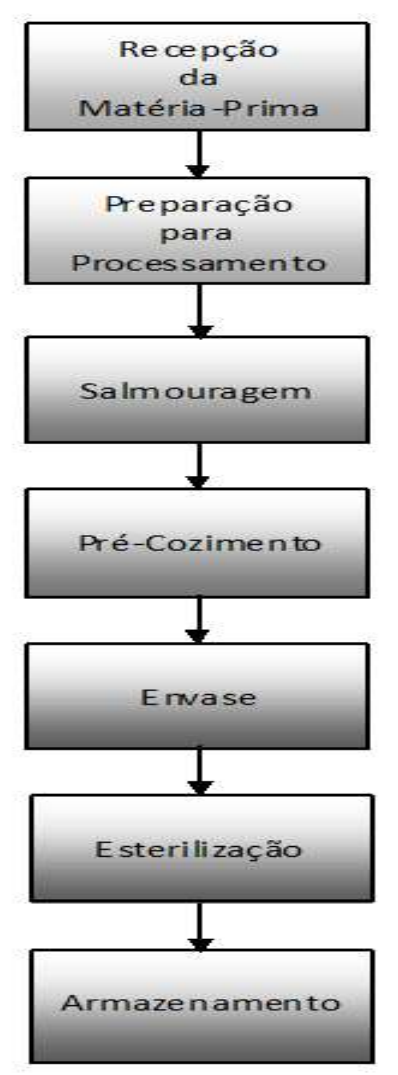

\section{FIGURA 2 - FLUXOGRAMA BÁSICO DE PROCESSAMENTO DE} PESCADO EM CONSERVAS 


\subsubsection{Recepção da Matéria-Prima}

A matéria-prima utilizada na fabricação de conservas pode ser recebida na forma resfriada ou congelada, dependendo do tempo de transporte entre a produção e as instalações de processamento. Sob resfriamento, a temperatura frequentemente recomendada para retardar as reações de deterioração é de $0^{\circ} \mathrm{C}$ e o pescado pode ser acondicionado em caixas plásticas com gelo e armazenado em câmara de refrigeração entre 1 e $2{ }^{\circ} \mathrm{C}$ (GARTHWAITE, 2010). Para espécies tropicais ou submetidas a grandes variações climáticas, Venugopal (2006) sugere a manutenção de temperaturas entre -1 e $1{ }^{\circ} \mathrm{C}$. Alternativamente, para pescado recebido na forma congelada (geralmente em blocos) a temperatura ideal de armazenamento é de $-30{ }^{\circ} \mathrm{C}$, especialmente para pescado gordo em razão da possibilidade de oxidação, cujo fenômeno evolui rapidamente em temperaturas tão baixas quanto $-18{ }^{\circ} \mathrm{C}$. $\mathrm{O}$ descongelamento deve ocorrer em ambiente com temperaturas entre $15 \mathrm{e} 20^{\circ} \mathrm{C}$, pois valores inferiores prolongam demasiadamente o processo, causam o amolecimento da textura e a redução de rendimento nas etapas posteriores de processamento (GARTHWAITE, 2010). Considerou-se o pescado descongelado quando a temperatura atinge $0{ }^{\circ} \mathrm{C}$ no seu interior para facilitar a obtenção de filés ou postas por processo manual. Temperaturas entre -2 e $-5^{\circ} \mathrm{C}$ podem ser empregadas para finalidades similares utilizando processos mecânicos, pois o pescado se encontra parcialmente descongelado (JAMES e JAMES, 2010).

Após o descongelamento é feita uma pré-seleção dos exemplares com base na aparência, dimensões, textura e outros critérios. Lavagens com água clorada são recomendadas para a eliminação de limo e sujidades na superfície do pescado antes do início do processamento.

\subsubsection{Preparação Para Processamento}

Basicamente, a preparação do pescado para processamento inicia pelas operações de descabeçamento, evisceração e remoção de partes não desejáveis (pele, escamas, espinha, cauda, nadadeiras, etc.). Como a implantação do processo de industrialização está associada ao aspecto econômico é preciso definir a forma e extensão da porção muscular desejada e o seu rendimento em relação ao pescado inteiro, o qual depende da estrutura anatômica da espécie. Segundo Venugopal (2006), a tilápia apresenta um dos menores rendimentos na obtenção de filé (33 \%) em comparação ao salmão (Salmo salar, maior que $50 \%$ ) e o catfish (Ictalurus punctatus, maior que $38 \%$ ), mas, na forma de postas, pode atingir entre 40 e $45 \%$ de rendimento. Batista (2005) observou rendimento de 50 \% na obtenção de "charutos" (porção muscular sem cabeça, vísceras e nadadeiras) para a tilápia-do-nilo a partir de exemplares com peso de $100 \mathrm{~g}$, enquanto Souza (2002) obteve $36 \%$ de rendimento máximo na filetagem de peixes com peso de $360 \mathrm{~g}$.

\subsubsection{Salmouragem}

Após a definição da forma e a porção muscular desejada ocorre a etapa da imersão em salmoura, cuja solução saturada corresponde a $36 \mathrm{~g}$ de cloreto de sódio por $100 \mathrm{~g}$ de água $\left(20^{\circ} \mathrm{C}\right)$ ou $26,5 \mathrm{~g}$ do sal por $100 \mathrm{~mL}$ de solução. A salmouragem é empregada como método para eliminar resíduos de sangue, promover o enrijecimento superficial e melhorar a aparência e o sabor do pescado. Segundo Venugopal (2006), o tempo usual para alcançar esses objetivos está entre 15 a 20 minutos de imersão em salmoura saturada, mas, soluções com concentrações de sal a partir de $50 \%$ de saturação também podem ser utilizadas (GARTHWAITE, 2010). A diferença entre a concentração do sal no tecido muscular e na salmoura torna-se importante para determinar a velocidade de penetração do sal no pescado (SHENDERYUK e BYLOWSKI, 1990). Consequentemente, salmouras mais concentradas contribuem para a realização de processos mais rápidos de salmouragem. Outros fatores devem ser considerados como a pureza do sal, temperatura da salmoura e o teor de gordura e dimensões do pescado. Para fins de processamento, a concentração de sal no produto final 
dependerá do tempo de imersão na salmoura, sendo definida comercialmente em função da preferência do mercado (GARTHWAITE, 2010).

\subsubsection{Pré-Cozimento}

O pré-cozimento é feito em vapor sob pressão atmosférica e serve para promover a desnaturação parcial das proteínas, liberando parte da água, a qual é descartada antes do fechamento da embalagem. A eliminação dessa etapa acarreta a exsudação da água durante a esterilização do produto, diluindo o líquido de cobertura. Quando o envase ocorre com óleo vegetal, a aparência do produto fica prejudicada pela presença do exsudado na forma de gotículas após a esterilização. O pré-cozimento também serve para reduzir o teor de matéria graxa (especialmente em pescado gordo) e melhorar sua textura, odor e sabor.

Em experimentos realizados com enlatamento de tilápia foram utilizados períodos de 20 a 50 minutos para o pré-cozimento (BATISTA, 2005; PIZATO et al., 2012). Por causa da liberação de liquido ocorre perda de peso da ordem de $20 \%$ (BATISTA, 2005).

Em espécies de grande porte, como o atum, o pré-cozimento deve ser efetuado em vapor sob pressão atmosférica até atingir $70^{\circ} \mathrm{C}$ na região da espinha central, podendo demorar cerca de 4 horas para a conclusão do processo. Após resfriamento durante 24 horas o peixe apresenta textura mais firme, o que facilita o manuseio nas operações de corte e retirada da cabeça, pele, espinha e carne escura, proporcionando produto com qualidade superior (GARTHWAITE, 2010).

Como o pré-cozimento afeta as características sensoriais e o rendimento do processo, devese dimensioná-lo experimentalmente para cada situação, determinando o tempo e a temperatura requeridos para obtenção do produto desejado.

\subsubsection{Envase}

No Brasil, as conservas geralmente têm como líquido de cobertura o óleo vegetal, salmoura ou molho de tomate com enchimento a quente e exaustão em vapor saturado para a remoção do ar antes do fechamento da embalagem. O líquido de cobertura acelera a transferência de calor para o pescado e minimiza o super-cozimento em regiões mais próximas das paredes da embalagem. Tradicionalmente, as latas estão associadas às conservas de pescado, mas, os pouches podem proporcionar uma redução de 30 a $50 \%$ no tempo de esterilização em comparação com latas cilíndricas de capacidade equivalente (GOPAL e SHANKAR, 2011; VENUGOPAL, 2006). Os pouches são estruturas laminadas flexíveis, geralmente constituídas de três camadas, sendo a do meio ocupada pela folha de alumínio com espessura de $12 \mu \mathrm{m}$ (mais comum) e as demais constituídas de poliéster e polipropileno, correspondendo às camadas externa e interna, respectivamente (GOPAL e SHANKAR, 2011; VENUGOPAL, 2006).

Os dois tipos de embalagem são capazes de proporcionar o fechamento hermético, mas exigem procedimentos diferentes durante o processo de esterilização. Em razão da expansão do conteúdo, em determinado momento a pressão no interior da embalagem supera a pressão da autoclave provocando tensões no seu corpo e área de fechamento. A manutenção de ar residual inferior a $2 \%$ do conteúdo da embalagem é desejável como método de controle. Ao contrário das latas, os pouches são mais sensíveis às diferenças de pressão devido sua natureza flexível e limitada resistência da termossoldagem (VENUGOPAL, 2006). Por essa razão, o processo de esterilização de produtos em pouches ocorre com sobre pressão (pressão adicional fornecida à autoclave para manter a integridade da embalagem). O valor adicional de pressão depende da temperatura do processo e das condições de enchimento do produto (temperatura, volume de ar residual, quantidade de líquido de cobertura, etc.). Para processos a $121{ }^{\circ} \mathrm{C}\left(1 \mathrm{kgf} / \mathrm{cm}^{2}\right)$ pode ser necessário acrescentar de 0,7 a $1,4 \mathrm{kgf} / \mathrm{cm}^{2} \mathrm{com}$ a introdução de ar comprimido durante o ciclo de esterilização (ITAL, 1990). 


\subsubsection{Esterilização}

A esterilização comercial tem a finalidade de assegurar a redução de esporos de Clostridium botulinum (tipos A e B) em 12 ciclos logarítmicos. O processo foi estabelecido com base na carga inicial de um esporo por grama de produto e considerando que a probabilidade de sobrevivência será no máximo de $10^{-12}$ (um esporo em um trilhão) (VENUGOPAL, 2006). A redução da carga inicial depende da magnitude do tempo e da temperatura de exposição, ou seja, da intensidade do processamento térmico.

Nos experimentos sobre o desenvolvimento de produtos costuma-se adotar o tempo e a temperatura de esterilização com base em trabalhos já existentes. Após o processamento, são realizadas análises microbiológicas para verificar se a condição de esterilidade comercial foi alcançada. Dessa forma o produto poderá sofrer alterações indesejáveis no aspecto sensorial ou, ainda, apresentar deterioração microbiológica causada por subprocessamento térmico, demandando mais tempo para a conclusão da pesquisa.

O procedimento adequado para assegurar a condição de esterilidade comercial depende do dimensionamento da intensidade do processamento térmico, representado por Fo e expressa em minutos. O valor mínimo recomendado é de 3 minutos, calculado com base nos parâmetros de resistência térmica dos esporos e tendo como referência a temperatura de 121,1 ${ }^{\circ} \mathrm{C}$ (SHAW, 2010; VENUGOPAL, 2006; GONÇALVES e GERMER, 1992). Geralmente, valores entre 6 e 14 minutos oferecem segurança microbiológica, mas o efeito do processamento térmico em outros atributos de qualidade também deve ser considerado (VENUGOPAL, 2006). Por exemplo, Batista (2005) obteve estabilidade microbiológica no enlatamento de tilápia-donilo ao molho, esterilizada a $121^{\circ} \mathrm{C}$ durante 15,20 e 30 minutos (o autor não apresentou cálculo de Fo). Como resultado, houve boa aceitação quanto ao sabor, textura, cor e odor, mas parte dos julgadores relatou ter dificuldade em fragmentar a espinha nas amostras dos dois primeiros tratamentos. Então, a segurança microbiológica é fundamental, porém o amolecimento da espinha é um atributo de qualidade importante para a aceitação desse tipo de produto. Estudo mais abrangente foi apresentado por DHANAPAL et al. (2010), que encontraram Fo $=6,94$ minutos como valor ótimo no processamento de tilápia ao molho "curry" acondicionada em pouches e esterilizada a $116^{\circ} \mathrm{C}$ por 50,24 minutos. As amostras processadas apresentaramse comercialmente estéreis e com vida útil de 360 dias à temperatura ambiente com base na avaliação sensorial.

Depois da esterilização o resfriamento do produto deve ocorrer em água clorada (2 a 5 ppm) e o mais rápido possível como prevenção contra a deterioração por termófilos, cuja resistência térmica dos esporos é maior que a do Clostridium botulinum, tomado como base no processo. Além disso, temperaturas finais inferiores a $40^{\circ} \mathrm{C}$ são recomendadas, principalmente para produtos formulados com condimentos e especiarias, os quais podem conter grande quantidade de esporos termofílicos. Após o resfriamento, as embalagens devem ser manuseadas adequadamente evitando pancadas, quedas ou choques que possam afetar a sua integridade (GAZE, 2010; GONÇALVES e GERMER, 1992).

Na produção industrial, a confiabilidade do valor de Fo depende de prévia avaliação das instalações de processamento térmico, incluindo a verificação dos sensores de temperatura e a realização de ensaios de distribuição de calor na autoclave e de penetração de calor no produto (SHAW, 2010; GONÇALVES e GERMER, 1992).

\subsubsection{Armazenamento}

As embalagens metálicas (latas) geralmente são colocadas em caixas de papelão para armazenagem paletizada, ou sob empilhamento que permita a circulação de ar em temperatura amena. O tipo de material de embalagem, as características do produto e as condições 
de processamento e armazenamento podem potencializar as reações de corrosão e sulfuração durante o armazenamento. Conservas com ácido acético e altos teores de cloreto de sódio ou óxido de trimetilamina favorecem as reações de corrosão. Por outro lado, quando compostos de enxofre entram em contato com o ferro ou estanho poderá ocorrer a formação dos respectivos sulfetos, reação conhecida como sulfuração ou marmorização, mais intensa em pH 6,0. A coloração escura desses compostos prejudica a aparência do produto, principalmente a do sulfeto de ferro que é pouco aderente na superfície da lata e se dispersa facilmente (ANJOS, 1991). No mercado norte-americano a aplicação de revestimentos com óxido de zinco é uma forma de minimizar esses problemas (PAGE, 2010).

\section{CONCLUSÃO}

O aproveitamento de tilápias com menor valor comercial como matéria-prima para a fabricação de conservas pode representar alternativa interessante para oferecer ao consumidor brasileiro produto de qualidade e rico em proteinas. $\mathrm{O}$ conhecimento tecnológico existente permite a continuidade de pesquisas com resultados promissores. Há que se avançar na busca por formas de melhorar a viabilidade ecônomica na produção e no processamento industrial (incluindo-se os subprodutos), de modo a aumentar a competitividade de toda a cadeia produtiva.

\section{ABSTRACT}

\section{THE POTENTIAL OF THE NILE TILAPIA FOR CANNING PROCESS}

Tilapia is a lean fish with white flesh and high protein content. It is a raw material with potential for the development of fish products ready for consumption for the domestic market as well for the international. This review article discusses the main aspects of canned fish processing, from reception of raw materials until the final product storage. Emphasis was given to the growth of tilapia production in Brazil and its quality for the processing of canned fish, considering the stunning methods, off-flavor problems and thermal processing. Analyzing the existing technological knowledge it is concluded that there are elements for the development of research with promising results.

This paper is a literature review on the main aspects of canned fish processing covering from reception of the raw materials until the final product storage. Emphasis was given on Brazilian tilapia production growth and their quality for canning process. Considering the existing technological knowledge it is concluded that there are elements for the development of research with promising results. At the same time, we must move forward in the search for ways to improve the economic viability and increase the competitiveness of the productive chain.

KEY-WORDS: DEPURATION; OFF-FLAVOR; FISH STUNNINGMETHODS; PROCESS YIELD; THERMAL PROCESSING.

\section{REFERÊNCIAS}

1 ALBUQUERQUE, W. F.; ZAPATA, J.F.F.; ALMEIDA, R. S. Estado de frescor, textura e composição muscular da tilápiado-Nilo (Oreochromis niloticus) abatida com dióxido de carbono e armazenada em gelo. Revista Ciência Agronômica, v.35, p.264-271, 2004.

2 ANJOS, V. D. A. Embalagem metálica para produtos cárneos e pescado termoprocessados. In: Embalagem para produtos cárneos. Campinas:Instituto de Tecnologia de Alimentos,1991.p.49-72. 
3 BATISTA, L. X. Tecnologia de produção de conserva de tilápia (Oreochromis niloticus, Linnaeus, 1758 - Linhagem chitralada). 2005. 37 f. Dissertação (Mestrado em Recursos Pesqueiros e Aquicultura) - Universidade Federal Rural de Pernanbuco, Recife, 2005.

4 BIATO, D. O. Detecção e controle de off-flavor em tilápia do Nilo (Oreochromis niloticus), por meio de depuração e defumação. 2005. 105 f. Dissertação (Mestrado em Ciências) - Escola Superior de Agricultura Luiz de Queiroz. Universidade de São Paulo, São Paulo, 2005.

5 BRASIL. Cultivo de tilápia na Itaipu pode dobrar produção de pescado no País. In: Itaipu Binacional. Sala de Imprensa. Brasília. Publicado em 05/06/2013. Disponível em <http://www.itaipu.gov.br/> Acesso em: 12 set. 2013.

6 BRASIL. Ministério da Agricultura, Pecuária e Abastecimento. Secretaria de Defesa Agropecuária. Departamento de Inspeção de Produtos de Origem Animal. Instrução Normativa ${ }^{\circ} 45$. Regulamento técnico de identidade e qualidade de conservas de peixes. Diário Oficial [da] República Federativa do Brasil, Brasilia, 14 de dezembro de 2011a. Seção 1, p.11-12. Disponível em: <http://www.agricultura.gov.br/> Acesso em: 07 nov. 2013.

7 BRASIL. Ministério do Desenvolvimento Indústria e Comercio Exterior. Secretaria de Comercio Exterior. Sistema de análise das informações de comercio exterior. Brasília, 2012. Disponível em <http://aliceweb2.mdic.gov.br> Acesso em: 05 set. 2013.

8 BRASIL. Ministério da Pesca e Aquicultura. Boletim Estatístico de Pesca e Aquicultura. Brasilia, 2011b. Disponível em <http://www.mpa.gov.br/> Acesso em: 19 set. 2013.

9 CASTAGNOLLI, N. Piscicultura de água doce. Jaboticabal: Fundação de Apoio a Pesquisa, Ensino e Extensão/ Universidade Estadual Paulista, 1992. 189p.

10 DHANAPAL, K; REDDY, G.V.S; NAYAK, B.B; BASU, S; SHASHIDHAR, K; VENKATESHWARLU, G; CHOUKSEY, M.K. Quality of ready to serve tilapia fish curry with PUFA in retortable pouches. Journal of Food Science 75 (1): S348-S354, 2010.

11 FIGUEIREDO JUNIOR, C. A. ; VALENTE JUNIOR, A. S. Cultivo de tilápias no Brasil: origens e cenário atual. In: XLVI Congresso da SOBER. Rio Branco-AC, 20 a 23 de julho de 2008. Anais... Sociedade Brasileira de Economia, Administração e Sociologia Rural, 9p. Disponível em: <http://www.sober.org.br>. Acesso em: 06 nov. 2012.

12 FAO.Food and Agriculture Organization of the United States. Fishery and aquaculture statistics. Rome, 2014.

13 FITZSIMMONS, K.R.; RAMOTAR, P.; CEROZI, B. Global production and markets 2013. In: $10^{\text {th }}$ International Symposium on Tilapia in Aquaculture. Jerusalem, Israel, Proceedings... October 6-10, 2013.

14 FIRETTI, R.; SALES, D.S.; SUSSEL, F. R.; WAKATSUKI, A. C. Aquicultura nacional mudou com a ração extrusada. Informa Economics FNP, 2011. Disponível em: http://www.informaecon-fnp.com. Acesso em: 10 out. 2013.

15 GARTHWAITE, T. Fish quality. In: BRATT, L (ed). Fish canning handbook. Singapore: Blackwell Publishing, 2010. p. 102-131.

16 GAZE, J. Principal causes of spoilage in canned fish products. In: BRATT, L (ed). Fish canning handbook. Singapore: Blackwell Publishing, 2010. p. 219-224.

17 GONÇALVES, J. R.; GERMER, S. P. M.(ed.) Princípios de esterilização de alimentos. Campinas: Instituto de Tecnologia de Alimentos. 1992. 116 p. Manual Técnico $n^{\circ} 10$.

18 GOPAL, T. K. S; SHANKAR, C. N. R. Quality and safety of packaging materials for aquatic products. In:ALASALVAR et al.(ed.) Handbook of seafood, quality, safety and health applications. $1^{\text {st }}$ ed.Singapore: Blackwell Publishing Ltd, 2011.cap.12, p.139-155.

19 ITAL. Instituto de Tecnologia de Alimentos. Alimentos enlatados: princípios de controle do processamento térmico, acidificação e avaliação do fechamento de recipientes. $4^{a}$.ed. traduzida. Campinas,1990, 239p.

20 JAMES, S. J.; JAMES, C. Design and operation of frozen cold stores. In: BRATT, L (ed). Fish canning handbook. Singapore: Blackwell Publishing, 2010. 132-150 p.

21 KUBITZA, F. Tilápia em água salgada: uma boa alternativa para estuários e viveiros litorâneos. Rio de Janeiro: Panorama da Aquicultura, v. 15, n. 88, março/abril, 2005, p. 14-18.

22 KUBITZA , F. O status atual e as tendências da tilapicultura no Brasil. Rio de Janeiro: Panorama da aqüicultura, mar/abr, 2011, p.10-19.

23 PAGE, B. Packaging formats for heat-sterilized canned fish products. In: BRATT, L (ed). Fish canning handbook. Singapore: Blackwell Publishing, 2010. Cap.07, p.151-178

24 PEDRAZZANI, A. N.; CARNEIRO, P.C.F.; KIRSCHNIK, P.G; MOLENTO, C.F.M. Impacto negativo de secção de medula e termonarcose no bem-estar e na qualidade da carne de tilapia-do-Nilo. Revista Brasileira de Saúde e Produção Animal. Universidade Federal da Bahia. Salvador, Bahia. v.10, n.1, p.188-197, jan/mar, 2009 
PIZATO, S.; KRAIESKI, J; SARMENTO, C; PRENTICE, C. Avaliação da qualidade tecnológica apresentada por tilápia do Nilo (Oreochromis niloticus) enlatada. Semina: Ciências Agrárias, Londrina, v. 33, n. 2, p. 667-674, abr. 2012.

26 RODRIGUES, T. P.; FREITAS, M. Q. MÁRSICO, E. T.; FRANCO, R. M.; MELLO, S. C. R. P.; COSTA, I.; ZÚNIGA, N. O. Avaliação da qualidade da tilápia do Nilo (Oreochromis niloticus) cultivada, eviscerada e estocada em gelo. Revista Brasileira de Ciência Veterinária. Universidade Federal Fluminense. Niterói. v. 15, n. 2, p. 67-71, maio/ago. 2008.

27 SHAW, G. Commercial sterility and the validation of thermal processes. In: BRATT, L (ed). Fish canning handbook. Singapore: Blackwell Publishing, 2010. p. 225-237.

28 SHENDERYUK, V.I.; BYLOWSKI, P. J. Salazón y escabechado del pescado. In: SIKORSKI, Z.E. (ed). Tecnologia de los productos del mar: recursos, composión nutritiva y conservación. Zaragoza: Editorial Acríbia, 1990. p.199-219.

29 SOCCOL, M.C.H. Otimização da vida útil da tilápia cultivada (Oreochromis niloticus), minimamente processada e armazenada sob refrigeração. 2002. 124f. Dissertação (Mestrado em Ciências) - Escola Superior de Agricultura Luiz de Queiroz. Universidade de São Paulo, São Paulo.

30 SOUZA, M. L. R.; MARANHÃO, T. C. F. Rendimento de carcaça, filé e subprodutos da filetagem da tilápia do Nilo, Oreochromis niloticus (L), em função do peso corporal. Acta Scientiarum, Maringá, v. 23, n. 4, p. 897-901, 2001.

31 SOUZA, M.L.R. Comparação de seis métodos de filetagem em relação ao rendimento de filé e de subprodutos do processamento da Tilápia-do-Nilo (Oreochromis niloticus). Revista Brasileira de Zootecnia, v.31, n.3, p.1076-1084, 2002.

32 SOUZA, S. M. G. S.; MATHIES, V. D.; FIORAVANZO, R. F. Off-flavor por geosmina e 2-Metilisoborneol na aquicultura. Semina: Ciências Agrárias, Londrina, v. 33, n. 2, p. 835-846, abr. 2012.

33 USDA. UNITED STATES DEPARTMENT OF AGRICULTURE- (USDA) 2012. Aquaculture Data. Economic Research Service. Disponível em <http://www.ers.usda.gov/data/Aquaculture/> Acesso em: 15 ago. 2013.

34 VENUGOPAL, V. Seafood processing: adding value through quick freezing, retortable packaging, and cook-chilling. USA: CRC Press, 2006.485 p.

\section{AGRADECIMENTOS}

Ao Conselho Nacional de Desenvolvimento Cientifico e Tecnológico (CNPq) pela concessão de Bolsa de Desenvolvimento Tecnológico e Extensão Inovadora ao autor principal. 